\title{
El incidente de impacto fiscal en la jurisprudencia de la Corte Constitucional y el Consejo de Estado
}

The fiscal impact incident in the jurisprudence of the Constitutional Court and the Council of State

Autor: Wilmer Jahir Sierra Fagua

DOI: https://doi.org/10.25058/1794600X.1795

\footnotetext{
SP MISIÓN JURÍDICA A 


\title{
EL INCIDENTE DE IMPACTO FISCAL EN LA JURISPRUDENCIA DE LA CORTE CONSTITUCIONAL Y EL CONSEJO DE ESTADO*
}

\author{
The fiscal impact incident in the jurisprudence of the \\ Constitutional Court and the Council of State \\ O incidente de impacto fiscal na jurisprudência do Tribunal \\ Constitucional e do Conselho de Estado
}

Wilmer Jahir Sierra Fagua ${ }^{a}$ wsierrafagua@yahoo.com

Fecha de recepción: 01 de abril de 2020 Fecha de revisión: 22 de abril de 2020 Fecha de aceptación: 05 de junio de 2020

\section{RESUMEN}

Este artículo de reflexión estudia la figura constitucional del incidente de impacto fiscal, implementada con el Acto Legislativo 003/2011, y se presenta en tres secciones; la primera abordará su origen; la segunda analizará sus contenidos específicos. Finalmente, en la tercera, se hará referencia a la jurisprudencia que la Corte Constitucional y el Consejo de Estado han proferido sobre el particular; acápite dentro del cual se expondrán las falencias de ese procedimiento judicial.

\footnotetext{
* Este es un artículo de reflexión, se realizó a fin de optar al título de Magister en Derecho en la Universidad Sergio Arboleda de Bogotá D.C.

a. Abogado de la Universidad Pedagógica y Tecnológica de Colombia-UPTC, especialista en Derecho Administrativo del Colegio Mayor Nuestra Señora del Rosario Bogotá D.C., especialista en Derecho Constitucional de la Universidad Nacional de Colombia, Magister en Derecho, Universidad Sergio Arboleda, graduado con los Honores Magna Cum Laude, Juez Promiscuo Municipal de Corrales, Boyacá.
} 
Importa precisar que este trabajo, en el trasfondo, examinará si con la implementación del Incidente de Impacto Fiscal: i) se han protegido los derechos de los ciudadanos beneficiarios del fallo judicial sobre el que este se inició; ii) si, por el contrario, se ha protegido el presupuesto de las entidades públicas; o en su defecto, si se han garantizado las dos o solo una de las ópticas descritas.

\section{PALABRAS CLAVE}

Derechos; separación de poderes; finanzas públicas; sostenibilidad fiscal, Incidente de impacto fiscal.

\section{ABSTRACT}

This reflection article studies the constitutional figure of the fiscal impact incident implemented by the Legislative Act 003/2011 and is presented in three sections, the first one will tackle its origin, the second will analyze its specific contents. Lastly, the third section will allude to the jurisprudence that the Constitutional Court and the Council of State have issued on the matter, section in which the flaws of this legal procedure will be exposed. It is important to specify that this study, in the background, will examine if with the implementation of the fiscal impact incident: i) the rights of citizens who have benefited from the court decision on which it was initiated have been protected; ii) if, on the contrary, the budget of public entities has been protected, or if not, if both or only one of the perspectives describred has been ensured.

\section{KEY WORDS}

Rights; separation of Powers; public finances; fiscal sustainability; fiscal impact incident.

\section{RESUMO}

Este artigo de reflexão estuda a figura constitucional do incidente de impacto fiscal, implementado com o Ato Legislativo 003/2011, e é apresentado em três seções; o primeiro tratará de sua origem; a segunda analisará seu conteúdo específico. Por fim, na terceira, será feita referência à jurisprudência que o Tribunal Constitucional e o Conselho de Estado se pronunciaram sobre a matéria; secção dentro da qual serão expostas as lacunas desse procedimento judicial. É importante referir que este trabalho, em segundo plano, irá analisar se com a implementação do Incidente de Impacto Fiscal: i) foram protegidos os direitos dos cidadãos beneficiados com a decisão judicial de que foi iniciada; ii) se, pelo contrário, o orçamento dos entes públicos estiver protegido; ou, na sua falta, se ambas ou apenas uma das ópticas descritas foram garantidas.

\section{PALAVRAS-CHAVE}

Direitos; separação de poderes; finanças publicas; sustentabilidade fiscal, Incidente de impacto fiscal.

\section{INTRODUCCIÓN}

Esta investigación se propuso resolver el siguiente problema jurídico: ¿La aplicación jurisprudencial del Incidente de Impacto Fiscal demuestra que se garantizan, protegen y materializan los derechos fundamentales de los ciudadanos así como las finanzas del Estado Colombiano?

El objetivo general fue determinar cómo ha influido la jurisprudencia de la Corte Constitucional y el Consejo de Estado en la materialización de los derechos de los ciudadanos colombianos cuando han decidido los Incidentes de Impacto Fiscal conforme al artículo 334 de la Constitución Nacional y la Ley 1695/2013.

Los objetivos específicos consistieron en precisar el origen, el concepto y el procedimiento del Incidente de Impacto Fiscal; identificar las reglas y las sub reglas que la Corte Constitucional y el Consejo de Estado a través de su jurisprudencia han establecido al fallar los Incidentes de Impacto Fiscal y advertir las falencias y/o bondades del Incidente de Impacto Fiscal, en la jurisprudencia de la Corte Constitucional y del Consejo de Estado.

En este punto, cabe anotar que el Incidente de Impacto Fiscal se originó en el Congreso de la Republica durante los debates que se suscitaron en torno a la aprobación del Acto Legislativo 003 de 2011, mediante el cual se estableció el principio de la Sostenibilidad Fiscal. Vale destacar que esta se pretendió implementar por el Gobierno como un derecho constitucional, generando amplias discusiones tanto en la Cámara de Representantes como en el Senado, dado que en la práctica se perseguía por parte del ejecutivo que todos los jueces al momento de entrar a 
amparar cualquiera de los derechos estatuidos en el plexo constitucional, siempre e inevitablemente estuviesen supeditados a sopesar los alcances económicos que sus decisiones generarían para las finanzas del Estado (Corte Constitucional, Sentencia C- 288/ 2012: 91-121).

Sin embargo, tal pretensión no fue acogida por el Congreso de la República que terminó por adecuar el proyecto radicado por el Ministro de Hacienda, encausándolo bajo tres mandatos que lo redefinieron por completo, el primero, al indicar que la Sostenibilidad Fiscal no sería un derecho sino un criterio orientador de la actividad de todas las ramas y autoridades del Estado colombiano, el segundo, en cuanto de forma enfática estableció que al interpretar los contenidos de la reforma: bajo ninguna circunstancia, autoridad alguna de naturaleza administrativa, legislativa o judicial, podría invocar la sostenibilidad fiscal para menoscabar los derechos fundamentales, restringir su alcance o negar su protección efectiva. Finalmente, el tercero, al crear el Incidente de Impacto Fiscal.

Esta última figura se encuentra regulada en el artículo 334 de la Constitución y en la Ley 1695/ 2013. En líneas generales, es un procedimiento especial y posterior al proceso, que facultó al Procurador General de la Nación y a uno de los ministros del Gobierno, para que una vez proferida una sentencia por cualquiera de las máximas corporaciones judiciales existentes en Colombia, a saber, Corte Constitucional, Consejo de Estado y Corte Suprema de Justicia, soliciten su tramitación obligatoria, siempre y cuando se altere la sostenibilidad fiscal de la entidad condenada, para ello es necesario que se proponga un plan para lograr su cumplimiento. En ese panorama, la corporación debe resolver si modula, modifica o difiere los efectos de su decisión.

En relación con lo señalado, en el lapso comprendido entre el 2012 y el 2019 y según las cifras de la Agencia Nacional de Defensa Jurídica del Estado, el pasivo contingente, entendido como el monto total de las demandas impetradas y en trámite en contra del Estado colombiano, fue superior al presupuesto general de la Nación liquidado por el Ministerio de Hacienda para esos años; en otras palabras, los presupuestos de la Nación en los años 2012 a 2019, de forma constante e invariable han sido insuficientes para pagar la totalidad de pretensiones dinerarias que cursan en su contra a través de procesos judiciales.

Sobre esa base, el incidente ha cobrado fuerza, en especial por decisiones dictadas por el Consejo de Estado y la Corte Constitucional, en las que han ponderado de forma directa la exigencia de un derecho concedido en una sentencia, en contraste con su impacto en las finanzas públicas. El Consejo de Estado se encargó del tema en el fallo condenatorio proferido en contra del Distrito Capital por el derrumbe del relleno sanitario "Doña Juana"; por su parte, la Corte Constitucional hizo lo propio en la sentencia C- 492/2015, que ordenó al Gobierno Nacional permitir la sustracción de las rentas de trabajo exentas, para el cálculo del impuesto a la renta, dentro de los métodos denominados "IMAN e IMAS-PE".

Cabe advertir que en lo atinente a la Sostenibilidad Fiscal como el género del tema propuesto es bastante amplia la literatura existente; en tanto que, es muy poco lo que se ha escrito, analizado y evaluado en relación con el Incidente de Impacto Fiscal como la especie de la temática planteada .

La situación es aún más compleja cuando se indaga por los fundamentos de las sentencias que el Consejo de Estado y la Corte Constitucional han emitido al respecto, pues no se encuentra literatura suficiente. En razón a lo expuesto, el estudio planteado pretende aportar elementos de juicio que contextualicen su estado actual, al exponer desde un análisis jurisprudencial sus bondades y falencias, de manera que a futuro esos argumentos sean rebatidos, revaluados y/o retomados por los interesados en ahondar en $\mathrm{su}$ estudio, además de exponer una visión analítica y crítica de la figura constitucional.

Adicionalmente, con la presente investigación se pretenden analizar los impactos y alcances que la jurisprudencia dictada por la Corte Constitucional y el Consejo de Estado ha tenido respecto de los derechos de los ciudadanos colombianos, de forma específica desde dos perspectivas, la primera, en lo que tiene que ver con los derechos de los beneficiarios de la condena sobre la cual se inicia el Incidente de Impacto Fiscal, la segunda, en cuanto atañe al presupuesto de las entidades estatales que realmente pertenece a todo el conglomerado social. 
Es dable manifestar que los resultados de la investigación arrojaron que la figura constitucional no satisface ninguna de las dos ópticas de los derechos indicados, por lo cual, se plantea como solución, que desaparezca del ordenamiento jurídico y, en su lugar, se permita a todos los jueces del país y no solo a las Altas Cortes, que dentro de los procesos que tramitan en las primeras instancias, puedan solicitar concepto no vinculante sobre las finanzas de la entidad a condenar, de manera que en el fallo se establezcan los plazos y demás aspectos necesarios para su pleno cumplimiento, sin necesidad de acudir a otros trámites posteriores como actualmente ocurre.

Asimismo, se debe destacar que el Incidente de Impacto Fiscal, en la práctica, ha perjudicado tanto a los beneficiarios de la condena, como al presupuesto de las entidades públicas, al desdibujar la separación de poderes y lesionar gravemente la autonomía judicial.

El estudio propuesto se desarrollará en tres capítulos que se denominarán: i) génesis del Incidente de Impacto Fiscal; ii) contenido específico del Incidente de Impacto Fiscal y iii) el Incidente de Impacto Fiscal. Aplicación concreta, alcances y perspectivas.

\section{METODOLOGÍA}

En la presente investigación se utilizó una metodología analítica, explicativa y propositiva, mediante la revisión y el análisis documental de literatura jurídica sobre el tema, revistas indexadas, análisis de jurisprudencia de la Corte Constitucional y del Consejo de Estado, con miras a proponer una solución al problema planteado. Para su desarrollo se acudió al uso de las herramientas descritas a continuación.

Consulta de Bases de Datos: Para este efecto se consultaron las bases de datos que ofrecen las universidades y bibliotecas, con el objeto de obtener la literatura necesaria para ahondar en los precedentes históricos - jurídicos que han desarrollado el tema, la llegada a nuestro sistema jurídico y el desarrollo que el mismo ha tenido.

Análisis de Jurisprudencia: La jurisprudencia de la Corte Constitucional y del Consejo de Estado, ofrecen sentencias sobre el tema en estudio, las cuales permitieron conocer el desarrollo jurisprudencial, partiendo desde luego de la muestra real que conllevó a que esta investigación sea valiosa.

Análisis Jurídico: Se estudiaron necesariamente todos los antecedentes Constitucionales y Legislativos, actualmente representados en el artículo 334 de la Constitución y en la Ley $1695 / 2013$.

\section{GÉNESIS DEL INCIDENTE DE IMPACTO FISCAL}

El IIF surgió por iniciativa del partido liberal, en el séptimo debate del Acto Legislativo 003 de 2011, por el cual se estableció el principio de Sostenibilidad Fiscal.

El Incidente de Impacto Fiscal (en adelante IIF), se originó en el Congreso de la Republica durante los debates que se suscitaron en torno a la aprobación del Acto Legislativo 003/2011; por el cual se estableció el principio de la Sostenibilidad Fiscal (en adelante SF). Sobre el particular, importa precisar que la SF se pretendió implementar por el Gobierno como un derecho, generando amplias discusiones (Gaceta del Congreso de 2010, Ponencia primer debate primera vuelta al proyecto de Acto Legislativo 016 de 2010 Cámara, 019 de 2010 Senado.p.1.).

En los debates que se dieron en el Congreso se registran argumentos a través de las cuales, los parlamentarios abiertamente promulgaban la necesidad de ponerle freno a las decisiones judiciales con alto impacto en las finanzas estatales, poniendo en evidencia que la reforma se dirigió a mitigar la intervención judicial en la economía, en especial, de la Corte Constitucional, llegando incluso a referirse a la "dictadura de los jueces" como la causa de la inviabilidad de las finanzas del Estado (Gómez, 2015:10).

En punto a lo anterior, es preciso manifestar que en la exposición de motivos del proyecto de Acto Legislativo 016/2010, Cámara, se planteó por el Ministro de Hacienda y Crédito Público, lo siguiente:

De este derecho se deriva el deber de todas las ramas y órganos del poder público para que sus decisiones sean acordes con la sostenibilidad fiscal para realizar los propósitos del Estado 
Social de Derecho. Es necesario tener una disposición constitucional expresa que contenga un derecho de todos, que garantice que el Estado tendrá las condiciones, dentro de sus propias limitaciones de recursos, de garantizar la prestación y el disfrute de los derechos económicos, sociales y culturales, y por ende una realización sostenible y eficiente del Estado Social de Derecho, al tiempo que imponga un deber a las ramas y órganos del poder público de proteger con sus decisiones y actuaciones el mencionado derecho. El propósito del Acto Legislativo que ahora se presenta, es señalar al Congreso, así como a los demás órganos del Estado en todos los niveles, y según sus competencias, el deber de buscar, en forma deliberada, que sus diferentes decisiones faciliten el logro de una sostenibilidad fiscal, como instrumento de protección de los derechos sociales de los colombianos, y como tal, de la realización de los fines del Estado Social de Derecho (p, 1).

A su vez, el Senador Juan Carlos Vélez Uribe, destacó:

En el año de 1991, esa Constitución estableció la posibilidad ya de que en la Rama Judicial del Poder Público tuviera iniciativa del gasto, algo que no había sucedido entonces empezamos a encontrar una serie de decisiones de diferentes jueces del país, pero sobre todo jueces constitucionales, o jueces actuando como jueces constitucionales definiendo temas de gasto, por ejemplo hemos traído aquí a colación algunas de las sentencias que han generado alguna preocupación, por ejemplo la sentencia que establece la obligación para que el Estado colombiano le garantice a los desplazados el poder volver a su estado anterior, cuánto cuesta esa sentencia hablan de 30 billones de pesos, y así hay otra serie de decisiones que hemos mirado y se ha puesto en colación los riesgos que podría tener este tipo de decisiones de sostenibilidad fiscal para las decisiones de los jueces relacionadas con la salud, sobre todo tutelas de salud (Gaceta del Congreso 491/2011: 5)

Sin embargo, la pretensión de SF como un derecho no fue acogida por el Congreso de la República, que terminó adecuando el proyecto, encausándolo bajo tres mandatos que lo redefinieron por completo. En este sentido, Gómez
(2015), indica que, entre la versión radicada por el Gobierno con la finalmente promulgada, se constatan dos modificaciones: i) se abandonó la iniciativa de un derecho a la Sostenibilidad Fiscal y se prefirió tipificar un criterio de Sostenibilidad Fiscal; ii) se introdujo en el séptimo debate por iniciativa del Partido Liberal, el Incidente de Impacto Fiscal, que no se preveía en el proyecto original. A ello se suma la formula según la cual, al interpretar los contenidos de la reforma, bajo ninguna circunstancia, autoridad alguna de naturaleza administrativa, legislativa o judicial, podrá invocar la Sostenibilidad Fiscal para menoscabar los derechos fundamentales, restringir su alcance o negar su protección efectiva.

En la Gaceta del Congreso 491/2011, se plasmó cuando se le concedió la palabra a los Senadores Luis Fernando Velasco Chaves y Jesús Ignacio García Valencia, que propusieron reformar el artículo $1^{\circ}$ del proyecto de Acto Legislativo e implementar un incidente constitucional, como condición para que el Partido Liberal acompañara la aprobación de la reforma constitucional.

Indicó el Senador Velasco Chaves:

Cómo lograr primero que más que un principio sea un criterio, entonces cómo lograr que la sostenibilidad fiscal que entre otras cosas la estamos debatiendo en una ley de la República que el partido ha venido ayudando deje de ser un principio rector y sea un criterio de evaluación y, segundo, ustedes no la han pensado señor Ministro y nosotros lo hemos pensado recuerde cuando nosotros hablamos de los fallos estamos hablando de un incidente constitucional. Esta mañana evaluábamos que particularmente en las tutelas, muchas veces hay fallos, señor Ministro, que mientras llegan a la Corte Constitucional pueden paralizar el gasto de un gobierno ahí le tenemos una propuesta (Gaceta del Congreso 491/2011: 5).

Y continúo el Senador Jesús Ignacio García Valencia:

Nosotros proponemos que la sostenibilidad fiscal se enuncie en la Constitución no como un principio sino como un criterio. Lo segundo es cierto que hay sentencias de los jueces constitucionales que tienen un impacto 
de carácter fiscal y que si se obliga a las autoridades del ejecutivo sobre todo a hacer efectivas esas sentencias ello puede dar al traste con la situación fiscal de las entidades territoriales llámense departamentos o municipios o de otro tipo de entidades que deban cumplir con las sentencias que dicten los jueces constitucionales. Entonces como la Corte Constitucional ya en diferentes materias ha venido dictando sentencias modulativas en las cuales precisamente en la medida en que se trata de hacer efectivos derechos de prestación difiere en el tiempo, el cumplimiento de los fallos o le permite mejor a las autoridades irlos cumpliendo de manera progresiva nosotros proponemos que se lleve a la Constitución una propuesta en virtud de la cual cuando el fallo del juez constitucional tenga impacto social el Ministerio Público o las autoridades del ejecutivo puedan plantear una incidente de impacto fiscal, con el objeto de que se discuta cuáles pueden ser los alcances del fallo que dicten los jueces constitucionales en las finanzas de los departamentos, de los municipios o de las entidades que tienen que cumplir con esos fallos de constitucionalidad o dictados por los jueces constitucionales y que como consecuencia de ese incidente se difiera en el tiempo o se pueda precisamente determinar por el juez que de manera progresiva se vaya haciendo el cumplimiento de los efectos de la sentencia (Gaceta del Congreso 491/2011: 6).

Sobre el último aspecto referido, sostiene Roa (2015), que si bien la Corte Constitucional en la Sentencia C-1052/2012 ${ }^{1}$, declaró que la inclusión del IIF en el séptimo debate no constituyó una violación del principio de identidad flexible establecido en el artículo 375 de la Constitución, este no es un argumento para negar que el IIF fue

1. A manera de conclusión, y a fin de justificar la constitucionalidad de su decisión, la Corte Constitucional expuso lo siguiente: "En definitiva, esta Sala reitera que el incidente de impacto fiscal es un procedimiento establecido como consecuencia de las deliberaciones surtidas en el Congreso de la República para establecer un espacio de diálogo y concertación entre el Gobierno, la Procuraduría General de la Nación y las altas cortes sobre el impacto de los efectos de las decisiones judiciales en la sostenibilidad fiscal del país, bajo la observancia de los parámetros antes anotados. También enfatiza en que la sostenibilidad fiscal es un criterio que el juez debe tomar en consideración al momento de medir el impacto de los remedios para proteger las garantías invocadas y no para definir el contenido de los derechos; pues, entenderlo en caso contrario, implicaría el desconocimiento del principio de autonomía judicial consagrado en el artículo 228 Superior" $(P, 99)$. aprobado sin deliberación de calidad porque fue propuesto en la parte final del trámite legislativo. Argumentos que resultan ciertos, puesto que una figura con tanta trascendencia en la materialización de los derechos de los ciudadanos, y que ha generado diversas controversias, sin lugar a dudas ameritaba discusiones más profundas y concienzudas. Propósito que no se logró por la forma cómo se incorporó en el penúltimo debate del Senado, excluyendo de esta forma a la Cámara de Representantes.

A propósito del origen del IIF, para Acevedo (2015), en la Unión Europea, a la inversa de lo que sucedió en Colombia, son los jueces de la Unión, a petición de uno de sus miembros, quienes pueden sancionar al Estado que no satisfaga la Sostenibilidad Fiscal; respalda su postura con el caso de Argentina, donde se creó por la Corte Suprema de Justicia (mediante acordada No. $36 / 2009$ ), una instancia técnica en su interior, a la cual se le puede solicitar una opinión fundada acerca de los efectos macroeconómicos, que derivarían las decisiones a proferir. Con base en lo expuesto, deduce que a nivel internacional la Sostenibilidad Fiscal no irrumpe directamente en la órbita judicial, como si sucede con el Incidente implementado en Colombia; además concluye que esta es una figura de creación propia de nuestro derecho (p, 10-12).

\section{CONTENIDO ESPECÍFICO DEL INCIDENTE DE IMPACTO FISCAL}

\section{Regulación del IIF de conformidad con el artículo 334 de la Constitución y la Ley $1695 / 2013$}

Restrepo (2015), destaca como características del IIF, las siguientes: i) es un espacio de interlocución entre los servidores públicos y las Altas Corporaciones; ii) es una decisión judicial no administrativa; si bien su trámite es obligatorio, la determinación del juez puede consistir en no aceptar las argumentaciones de la administración y, por lo tanto, abstenerse de aplicar el incidente; iii) es una figura instrumental, en el sentido que las Altas Cortes, pueden considerar, luego de adoptar su decisión, los efectos fiscales que puede tener su cumplimiento; iv) es una decisión jurisdiccional que debe motivarse, sin que el principio de la cosa juzgada deba verse alterado en modo alguno. En lo atinente a los efectos prácticos del IIF indica 
los siguientes: i) no es obligatorio para el Juez acoger favorablemente la solicitud de IIF; ii) si se acepta, son tres las modalidades de su aplicación: modificación, modulación o diferimiento de los efectos de carácter fiscal de la sentencia. En punto a la modificación de los fallos, plantea que puede llegar a vulnerar la cosa juzgada. Porque:

No está del todo vedada la posibilidad de modificar la sentencia, por lo que se va presentar una tenue línea de ambigüedad cuando de modificar los efectos del fallo se trate, contexto sobre el que: solamente la jurisprudencia habrá de calificar cuáles son los linderos y los alcances (Restrepo, 2015: 708).

En ese contexto, en la actualidad, el IIF se encuentra tipificado en el artículo 334 de la Constitución y en la Ley 1695/2013; la norma constitucional lo pregona como la competencia que se le atribuyó al Procurador General de la Nación y a uno de los ministros del Gobierno, para que una vez proferida una sentencia por cualquiera de las máximas corporaciones judiciales existentes en Colombia (entiéndase Corte Constitucional, Consejo de Estado y Corte Suprema de Justicia), soliciten su tramitación obligatoria. Entre tanto, el precepto legal establece el procedimiento que se debe seguir, así como los términos específicos que rigen cada una de las etapas que este prevé. Así:

Procede frente a las sentencias emitidas por cualquiera de las máximas corporaciones judiciales y también contra los autos posteriores. Del incidente conocerá la Sala Plena de la corporación a la que pertenezca el magistrado que presentó la ponencia de la sentencia o auto sobre el que se solicita el Incidente. Durante el trámite pueden intervenir: i) el solicitante (Procurador General de la Nación o uno de los ministros de Gobierno); ii) el ministro de Hacienda y Crédito Público; iii) los demandantes y demandados que fueron parte en el proceso.

Sobre este tópico, Roa (2015), considera que el IIF es un recurso y no un incidente. Sostiene que la teoría conocida como el constitucionalismo débil admite que los jueces dicten sentencias con contenido económico, hipótesis frente a la cual se han planteado dos reacciones, unas de tipo democrático y otras de tipo tecnocrático $(p, 8)$.
Dentro de las primeras, destaca las legislativas, que se encuentran en los sistemas constitucionales del Reino Unido y Canadá.

El primero es el modelo de control judicial establecido mediante la Human Rights Act de 1998, que faculta a los jueces para emitir declaraciones de incompatibilidad de una ley, ante las cuales, el Parlamento asume la competencia definitiva de decisión sobre la derogación o modificación de la ley, lo cual puede hacer mediante un procedimiento legislativo expedito. El segundo ejemplo es el artículo 33 de la Carta Canadiense de Derechos y Libertades de 1982, que establece la denominada cláusula, no obstante, por medio de la cual, el legislador puede proteger una ley ante decisiones judiciales de inconstitucionalidad, mediante la aprobación de una salvaguarda que mantiene vigente la ley, no obstante, la decisión judicial, por periodos de cinco años que pueden ser renovados indefinidamente (Roa, 2015: 9-10).

Frente a las segundas, sostiene que provienen del poder ejecutivo y que tienen en cuenta los argumentos de técnica económica del gobierno. En estas enmarca al IIF y asevera que, con las dos reacciones referidas, se despoja al juez de la última palabra en materia de protección de derechos y se asigna la decisión final al legislador o al ejecutivo, situación que puede desembocar en ciertas problemáticas, ya que el juez puede tomar dos posturas:

De una parte, una exagerada generosidad en la protección de los derechos constitucionales porque sabe que el ejecutivo bloqueará su decisión mediante el IIF. De esta manera, ante la opinión pública el juez aparecerá como el protector de los derechos y el ejecutivo como un obstáculo para su garantía. Creando así un gran populismo judicial y conflictos entre los poderes públicos. Por otro lado: el juez puede proponerse evitar el bloqueo de sus decisiones mediante el Incidente de Impacto Fiscal y asumir una espontánea y exagerada restricción que torne ineficaz el sistema judicial de garantía de los derechos (Roa, 2015: 19-20).

En último lugar, sostiene que no existen razones claras del por qué se facultó al Procurador para interponer el IIF, cuando aquel, 
conforme a las competencias atribuidas en el Decreto 262/2000, artículo 7-12, interviene exponiendo su postura como parte dentro del proceso judicial. Adicionalmente, el IIF pretende que una voz económica, consecuencialista, autorizada y especializada sea escuchada en el proceso de deliberación institucional sobre la protección de un derecho. Sin embargo, ninguna de estas condiciones está asignada a la Procuraduría General de la Nación, porque su posición institucional no la destaca como técnico especialista en asuntos económicos (Roa, 2015: 23).

En este sentido, se considera que no es cierto que con el IIF se despoje al juez de la última palabra en materia de protección de derechos, pues su tramitación no es camisa de fuerza que garantice que se acceda a las pretensiones que se invocan; aunque, en todo caso, no puede dejarse de lado que con la figura constitucional en estudio, el Ejecutivo sí adquirió nuevas competencias que permearon directamente la función judicial, dado que al activar el incidente, se obliga a la Alta Corporación a estudiarlo, y si es del caso, con los argumentos presentados, a variar el cumplimiento de su decisión judicial.

En cuanto al interrogante referente a la facultad otorgada al procurador para solicitar el IIF, sin ser un organismo técnico o económico, puede tener asidero, porque las competencias que a ese funcionario se le otorgaron constitucionalmente en el artículo 277, no refieren directamente al manejo de asuntos económicos, por el contrario, su esencia es la protección de los derechos del conglomerado social (en general). Podría llegar a entenderse que esa nueva función se acompasa porque las finanzas públicas son un asunto que interesa a todos los ciudadanos; sin embargo, al ser el garante de los derechos, debe velar de forma objetiva e imparcial, para que ese postulado se cumpla a unos como a otros, y con el inicio del Incidente quedan suspendidos los derechos de los beneficiarios de la sentencia, circunstancia que en la práctica significa una desprotección en su favor, al tener que esperar un tiempo indeterminado para obtener su cumplimiento efectivo.

Ahora bien, la solicitud de apertura se radicará ante el magistrado ponente de la sentencia o auto posterior y dentro del término de su ejecutoria. Si la petición se presenta dentro de ese plazo, el magistrado lo concederá dentro de los 5 días hábiles siguientes. A partir de ese momento, el solicitante cuenta con 30 días hábiles para sustentarlo, so pena que se declare desierto.

El escrito de sustentación debe contener: i) las posibles consecuencias de la providencia en la sostenibilidad de las finanzas públicas; ii) las condiciones específicas que explican dichas consecuencias; iii) los planes concretos para el cumplimiento de la sentencia o autos posteriores, que aseguren los derechos reconocidos en ella, en un marco de Sostenibilidad Fiscal; a la vez, debe adosarse un concepto expedido por el Ministerio de Hacienda y Crédito Público.

Si el escrito que sustenta el IIF posee algún defecto o se encuentra incompleto, se inadmitirá, para que dentro de los 5 días siguientes el solicitante incluya específica y puntualmente los elementos que requieren mayor detalle, contra la inadmisión procede el recurso de reposición. Por el contrario, si satisface los requerimientos descritos, la corporación judicial lo admitirá mediante auto no pasible de recursos y dispondrá: i) que se notifique por estado al solicitante, al Ministerio de Hacienda y Crédito Público y a las partes que conforman el proceso; ii) que se fije fecha para la audiencia de impacto fiscal, la cual deberá celebrarse dentro de los 3 días siguientes a la notificación por estado de todas las partes; iii) la suspensión de los efectos de la sentencia o de los autos proferidos con posterioridad; hasta que se decida si procede a modular, modificar o diferir sus efectos. Una vez se ordene su admisión, queda vedado el desistimiento.

En la audiencia de impacto fiscal, el solicitante explicará las consecuencias de la sentencia o auto posterior, para las finanzas públicas, así como el plan concreto para su cumplimiento, con la participación obligatoria de las partes del respectivo proceso, quienes podrán presentar su posición. La intervención del Ministerio de Hacienda y Crédito Público, así no haya sido quien promovió el incidente, es obligatoria.

Una vez realizada la audiencia, dentro de los 10 días siguientes, la Sala plena de la corporación que dictó la sentencia o el auto sobre el que solicitó la apertura del Incidente, deberá decidir por mayoría si modula, modifica o difiere sus efectos; en todo caso, no podrá cambiar el sentido el fallo. Debe advertirse que la decisión de acceder a las peticiones del escrito que contiene el incidente 
son potestativas de la respectiva corporación. Ello significa que con la apertura y trámite del IIF, de ninguna manera se asegura que los efectos de la providencia vayan a variar.

Resuelto el anterior, dentro de los tres días se podrá interponer el recurso de insistencia ante la corporación que lo resolvió, suspendiendo los efectos de la decisión; si el fallo es adverso a la parte que lo solicitó, el gobierno deberá cumplir la sentencia sin dilación alguna.

Con relación a lo indicado, para Monroy (2015), la Ley 1695/2013, transgrede la Constitución, ya que en el Acto Legislativo 03/2011, nunca se hace referencia a autos, sino solo a sentencias y su plan de cumplimiento; igualmente, el artículo 13 de la Ley 1695/2013, vulnera los principios de igualdad y debido proceso, en tanto que, contra la providencia que falle el IIF procederá recurso de insistencia que suspenderá los efectos del fallo, mientras que el ciudadano del común y corriente no puede recurrir la decisión, en caso de ser negativa a sus intereses; es decir, el IIF excluye a la contraparte del gobierno que logró la justiciabilidad de un derecho (p, 15-16).

López (2012), concluye que el IIF no es el medio más idóneo para evitar que los jueces sigan ordenando gasto, porque quedó limitado a las Altas Cortes, de modo que los tribunales y jueces de instancia, que también pueden ordenar gastos por medio de sentencias, quedaron por fuera del campo de acción de la norma $(p, 17)$.

Frente a la presunta vulneración de los principios de igualdad $\mathrm{y}$ debido proceso considero que no es acertada, ya que la Ley 1695/2013, artículo 13, al regular el recurso de insistencia no expuso como único legitimado al solicitante; de manera que los beneficiarios del fallo también podrán alegarlo, cuestión que así fue entendida por la Corte Constitucional en la sentencia C- 870/2014, párrafo 3.5.5.2.22. Lo atinente a la postura de la limitación del incidente únicamente a las Altas Cortes, se comparte plenamente, ya que, por ejemplo, los tribunales y

2. Indicó el Tribunal Constitucional: “(...) no admite discusión alguna, que la norma acusada, bajo una perspectiva general, vinculó la procedencia del aludido recurso al fallo que resuelve el incidente, sin importar el sentido de la decisión adoptada, y sin consagrar reglas restrictivas respecto de los legitimados para promover su procedencia, por lo que caben todos los sujetos que por ley tienen la condición de partes. juzgados administrativos del país pueden emitir cuantiosas condenas en contra del Estado que, sin lugar a dudas, al igual que los fallos de las altas corporaciones, impactan negativamente el presupuesto público, aspecto que se desconoció con el Acto Legislativo 03/2011.

Mientras tanto, antes de tomar sus decisiones, las altas corporaciones judiciales podrán solicitar la intervención del Ministerio de Hacienda y Crédito Público, a fin de conocer su opinión sobre los efectos de la controversia en la sostenibilidad de las finanzas públicas y plantearle interrogantes puntuales sobre temas de su competencia, los que una vez resueltos no serán vinculantes.

Ahora bien, con la finalidad de evitar alteraciones en la Sostenibilidad Fiscal de las entidades territoriales, el juez al momento de proferir una sentencia que condene a un municipio o departamento, deberá tener en cuenta su capacidad fiscal para dar cumplimiento a lo ordenado, para tal efecto, cualquiera de las máximas corporaciones judiciales podrá, durante cualquier etapa del proceso, solicitar al representante legal de la entidad territorial, que emita concepto sobre los efectos de una eventual condena en sus finanzas públicas. En último lugar, se le confiere la competencia al Procurador General de la Nación y a los ministros del Gobierno, para que cuando una Alta Corporación profiera una sentencia condenatoria en contra de un departamento o un municipio, soliciten en su favor el inicio del IIF.

No puede dejarse de mencionar que la Corte Constitucional en la sentencia C- 870/ 2014, sostuvo que el IIF regulado por la Ley 1695/2013, no procede contra las sentencias y autos dictados en materia de tutela, dado que para reglar esa clase de asuntos se debe acudir inexcusablemente a una ley estatutaria, particularidad que no posee la referida norma.

En este punto, vale la pena destacar la existencia de un grupo de autores que al estudiar el IIF, concluyeron que vulnera los principios de cosa juzgada, separación de poderes y autonomía e independencia de los jueces.

Concretamente, Barbosa (2014), considera que el IIF vulnera los principios constitucionales de cosa juzgada y separación de poderes, básicamente porque: i) se permite modificar o 
diferir los efectos de la decisión; ii) al otorgársele la potestad a los ministros y procurador de pronunciarse sobre la forma como se va a cumplir el respectivo fallo, se desequilibra a la Rama Judicial como poder público, situaciones que a su vez, pueden generar una condena contra el Estado colombiano en la Corte Interamericana de Derechos Humanos, en tanto que, ese organismo en casos similares (Furlan y familiares contra Argentina), ha condenado a Estados cuando han incurrido en violación de derechos humanos, reparando a las víctimas, pero no garantizando los derechos reconocidos en sede judicial, impidiendo el cierre definitivo de los procesos por la discusión de sus efectos económicos (p, 11). El autor destaca que la instancia judicial internacional se pronunció bajo los siguientes argumentos:

La Corte reitera que la ejecución de las sentencias debe ser regida por aquellos estándares específicos que permitan hacer efectivos los principios, inter alia, de tutela judicial, debido proceso, seguridad jurídica, independencia judicial, y estado de derecho. La Corte concuerda con el Tribunal Europeo de Derechos Humanos al considerar que para lograr plenamente la efectividad de la sentencia la ejecución debe ser completa, perfecta, integral y sin demora (CIDH, sentencia de 31 de agosto de 2012, párrs. 209 y 210: 11).

Rodríguez (2014), comparte la tesis referente a que, con el IIF, se ocasionó una concentración de poder por parte del ejecutivo, pues si bien debe responder por las obligaciones judiciales que se le imponen, este cumplirá las sentencias con un plan diseñado por él mismo y con el objetivo de no violar los límites impuestos en sus planes económicos como Rama del Poder Público.

Arango (2012), refiere que el IFF viola los principios de separación de poderes y de autonomía o independencia de los jueces, porque la intervención de otro órgano del Estado sin carácter judicial, pretende reabrir, sin la presencia de los titulares de los derechos afectados, un asunto ya decidido autónomamente por los jueces siguiendo el debido proceso ( $\mathrm{p}, 70-72$ ).

Aguilera (2014), sostiene que el IIF vulnera el principio de separación de poderes, puesto que el operador judicial llevará a cabo la valoración de los derechos en términos económicos y presupuestales y no desde la perspectiva de obligatoriedad y cumplimiento que plantea la Constitución, lo que significa un retroceso frente a los logros del Estado Social de Derecho ( $p$, 132-133).

En palabras de Guerrero (2012), para el Gobierno y Congreso colombianos, las decisiones judiciales de reconocimiento y garantía de los Derechos Económicos Sociales y Culturales, son la fuente de los desequilibrios presupuestales estatales, olvidando que son otros los factores que con más fuerza e intensidad inciden en ellos, tales como el gasto público exagerado y la corrupción rampante. También sostiene que el IIF conlleva a una confusión de funciones entre el Gobierno y la Judicatura, ya que se propicia un control administrativo hacia el órgano jurisdiccional y a una vulneración de los principios de tridivisión de poderes, legalidad y seguridad jurídica (p, 28-30).

En relación con esas posturas, sea lo primero decir que según la Corte Constitucional, tales argumentos no son válidos, y que por ende, el IIF sí se acompasa con la Carta Política (Sentencia C-288/2012); sin embargo, no se puede desconocer que de llegar a presentarse una mora en el cumplimiento y satisfacción de las condenas judiciales, como lo indicó Barbosa (2014), es latente que la Corte Interamericana de Derechos Humanos condene internacionalmente al Estado Colombiano, y las razones se refuerzan con lo expuesto por Rodríguez (2014), Arango (2012) y Aguilera (2014), puesto que, si bien es cierto, el poder ejecutivo no se está apartando del cumplimiento de las órdenes judiciales impuestas en su contra, no es lo menos que sí se está reservando para sí la potestad de indicar bajo qué términos, condiciones, plazos y en general desea hacerlo, generando para los beneficiarios de la condena incertidumbre y falta de credibilidad en las instancias judiciales.

Lo expuesto obedece a que ahora debe sumársele a los largos periodos que toma litigar un proceso en sus diferentes instancias, los nuevos términos que se le pueden otorgar a la entidad estatal para cumplir la totalidad de las obligaciones impuestas, pues es esta la que propone el plan de cumplimiento conforme a sus cálculos y operaciones financieras, pero, sobre todo, a su conveniencia, o según García Pérez, "a la resistencia indomable de la Administración a 
resolver expresamente todos sus procedimientos" (2013: 59).

Finalmente, y al contrario de las conclusiones antes referidas, Gómez (2015), expresa que la Sostenibilidad Fiscal y el IIF, en la práctica no han producido consecuencias que sobresalgan. Afirma que, si bien se observa una modificación interna en el ejecutivo, referida especialmente a las estrategias que puede aplicar ante las presiones provenientes del gasto, este cambio no tiene la entidad necesaria para acabar con los derechos sociales, con la acción de tutela o con el Estado social de derecho, a su modo de ver, por el contrario, puede ser un cambio saludable para el Estado (p, 20-21).

Este criterio se comparte con restricciones, básicamente, porque de un lado, como se verá en los capítulos siguientes, es cierto que el IIF no fue una hecatombe y en la práctica no acabó con los derechos sociales y menos aún con el Estado Social de Derecho; no obstante, con ello no se puede desconocer que sí existió una atribución de nuevas facultades y competencias en cabeza del Ejecutivo que descontrolaron el balance de poderes respecto de la Rama Judicial, ocasionando problemas en la materialización de los derechos de los ciudadanos colombianos; si bien no son muchos los ejemplos prácticos, los que existen demuestran que tal y como está estructurada, la figura en estudio es poco benéfica para la generalidad del conglomerado social; motivos que lleva a que esta investigación se aparte del calificativo "cambio saludable".

\section{EL INCIDENTE DE IMPACTO FISCAL. APLICACIÓN CONCRETA, ALCANCES Y PERSPECTIVAS.}

\subsection{El pasivo contingente del Estado Colombiano, según las cifras de la Agencia Nacional de Defensa Jurídica del Estado y del Ministerio de Hacienda superó el presupuesto total de la Nación para las vigencias fiscales 2012 a 2019}

En palabras de la Corte Constitucional, en Sentencia C-783/1999, una de las variables macroeconómicas más importantes para conservar el adecuado equilibrio de las finanzas estatales y que presenta un trascendente significado dentro de los diversos indicadores de la economía es la deuda pública; de ahí que, el Estado, en su conjunto, esté obligado a adoptar todas las medidas que resulten necesarias para garantizar su planeación y control, con el objetivo de que su monto se conozca con certeza $\mathrm{y}$ se encuentre suficientemente garantizado con los recursos estatales con que se dispone. Por tal razón, las obligaciones contingentes de la Nación, las entidades territoriales y las entidades descentralizadas de cualquier orden, claramente forman parte de esa deuda pública (p, 12-13).

Fluye de lo anterior, que las obligaciones contingentes juegan un papel importante dentro de la contabilidad del Estado en todos sus niveles; así las cosas, estas deben mantenerse siempre calculadas, para que se tomen de forma preventiva, las medidas necesarias a fin de corregir sus posibles desequilibrios en caso de hacerse exigibles.

Lo antepuesto cobra una gran relevancia, especialmente al indagar sobre el monto de las pretensiones económicas que a través de demandas se persiguen en contra del Estado colombiano. Frente al tema, la Agencia Nacional de Defensa Jurídica (ANDJ), emitió el documento que denominó: Informe de Gestión Anual 2019, mediante el cual, entre otras cosas, expuso que en 2019, participó en 500 procesos con pretensiones por 255 billones de pesos equivalente a un $68 \%$ del valor de las pretensiones de todas las demandas contra el Estado $(p, 4)$.

Esas cifras son bastante robustas, en tanto que, el presupuesto de toda la Nación para el año 2019, según lo expuesto por el Ministerio de Hacienda en el Decreto $2467 / 2018$, por el cual se liquidó el Presupuesto General de la Nación para la vigencia fiscal de 2019, equivalió a: doscientos cuarenta y cuatro billones novecientos noventa y siete mil trescientos cinco millones doscientos nueve mil novecientos veintisiete pesos moneda legal $(\$ 244,997,305,209,927)$; es decir, que para el año 2019, el monto total del presupuesto establecido para la Nación fue insuficiente para pagar la integridad de demandas que cursaban en su contra. Lo mismo sucede para los años 2012 a 2018, como a continuación se describe en la tabla número 1 , que se denomina pasivo contingente: 
TABLA NO. 1. COMPARACIÓN PASIVO CONTINGENTE VS. MONTO DEL PRESUPUESTO GENERAL DE LA NACIÓN

\begin{tabular}{|c|c|c|}
\hline AÑO & PASIVO CONTINGENTE & $\begin{array}{c}\text { MONTO DEL PRESUPUESTO GENERAL } \\
\text { DE LA NACIÓN, SEGÚN EL MINISTERIO } \\
\text { DE HACIENDA }\end{array}$ \\
\hline 2012 & $\begin{array}{l}\text { A } 31 \text { de diciembre de } 2012 \text {, había en el siste- } \\
\text { ma } 630 \text { procesos de más de } 20 \text { mil millones } \\
\text { y que concentran el } 76 \% \text { de las pretensiones } \\
\text { reportadas en el sistema, que ascienden en } \\
\text { total a } 214 \text { billones (ANDJE, 2012). }\end{array}$ & $\begin{array}{l}\text { Mediante Decreto } 4970 / 2011 \text { ( } 30 \text { de diciembre), se } \\
\text { estableció el presupuesto general de la Nación para el } \\
\text { año } 2012 \text {, en el monto de: ciento sesenta y cinco billo- } \\
\text { nes doscientos setenta y seis mil trescientos dieciocho } \\
\text { millones dos mil quinientos trece pesos moneda legal } \\
(\$ 165,276,318,002,513) \text {. }\end{array}$ \\
\hline 2013 & 190.9 billones (ANDJE, 2013). & $\begin{array}{l}\text { A través del Decreto } 2715 / 2012 \text { ( } 27 \text { de diciembre), se } \\
\text { estipuló el presupuesto general de la Nación para el } \\
\text { año } 2013 \text {, en ciento ochenta cinco billones quinientos } \\
\text { veinticuatro mil seiscientos treinta y tres millones se- } \\
\text { tecientos diecisiete mil seiscientos treinta y seis pesos } \\
\text { moneda legal }(\$ 185,524,633,717,636) \text {. }\end{array}$ \\
\hline 2014 & $\begin{array}{l}\text { Para el } 31 \text { de diciembre de } 2014 \text { se en- } \\
\text { cuentran registrados en el Sistema 393.851 } \\
\text { procesos activos en contra de la Nación por } \\
\text { un valor de } \$ 226 \text { billones en pretensiones } \\
\text { (ANDJE, 2014). }\end{array}$ & $\begin{array}{l}\text { En el Decreto } 3036 / 2013 \text { ( } 27 \text { de diciembre), se fijó } \\
\text { el presupuesto para el año } 2014 \text {, en: ciento noventa } \\
\text { y nueve billones ochocientos cincuenta y cuatro mil } \\
\text { quinientos cuarenta y siete millones quinientos vein- } \\
\text { tiún mil quinientos treinta y cinco pesos moneda legal } \\
(\$ 199 ; 854,547,521,535) \text {. }\end{array}$ \\
\hline 2015 & $\begin{array}{l}\text { A diciembre se registró un total de } 459.479 \\
\text { procesos con pretensiones por valor de } \\
\$ 3.322 \text { billones, } 699 \text { de estos procesos co- } \\
\text { rresponden a procesos cuyas pretensiones se } \\
\text { ubican en los de mayor cuantía y representan } \\
\text { un total de } \$ 3.243 \text { billones. Las pretensio- } \\
\text { nes en contra del Estado se incrementaron } \\
\text { considerablemente para el mes de diciembre } \\
\text { debido a que ingresó una acción de grupo } \\
\text { que involucra a todos los desplazados del } \\
\text { país y que tiene unas pretensiones de } \$ 3.057 \\
\text { billones. Sin este proceso las pretensiones en } \\
\text { contra del Estado sumarian } \$ 265,2 \text { billones y } \\
\text { las pretensiones de los } 681 \text { procesos de ma- } \\
\text { yor cuantía sumarian } \$ 184 \text { billones (ANDJE, } \\
\text { 2015). }\end{array}$ & $\begin{array}{l}\text { Con el Decreto } 2710 / 2014 \text { ( } 26 \text { de diciembre), se de- } \\
\text { terminó que el presupuesto para el año } 2014 \text {, estaría } \\
\text { en la suma de: doscientos tres billones seiscientos } \\
\text { cincuenta y ocho mil sesenta y tres millones cuatro- } \\
\text { cientos treinta mil trescientos ocho pesos moneda } \\
\text { legal }(\$ 203,658,063,430,308) \text {. }\end{array}$ \\
\hline 2016 & $\begin{array}{l}\text { La Agencia Nacional de Defensa Jurídica } \\
\text { (ANDJ) emitió el documento que denominó: } \\
\text { Informe de Gestión Anual 2016, mediante el } \\
\text { que, entre otras cosas, expuso que a } 31 \text { de } \\
\text { diciembre de } 2016 \text {, participa en } 377 \text { proce- } \\
\text { sos con pretensiones por } \$ 3.190 \text { billones de } \\
\text { pesos equivalente a un } 91 \% \text { del valor de las } \\
\text { pretensiones de todas las demandas contra } \\
\text { el Estado, que a esa fecha se encontraban } \\
\text { registradas, los cuales son } 539.061 \text { procesos } \\
\text { activos con pretensiones por } \$ 3.507,7 \text { billo- } \\
\text { nes (ANDJE, 2016). }\end{array}$ & $\begin{array}{l}\text { El presupuesto de toda la Nación para el año } 2016 \text {, } \\
\text { según lo expuesto por el Ministerio de Hacienda } \\
\text { en el Decreto } 2550 / 2015 \text {, por el cual se liquidó el } \\
\text { Presupuesto General de la Nación para la vigencia } \\
\text { fiscal de } 2016 \text {, equivalió a: doscientos quince billones } \\
\text { novecientos catorce mil trescientos sesenta y un millo- } \\
\text { nes novecientos sesenta y seis mil ciento nueve pesos } \\
(\$ 215,914,361,966,109) \text {. }\end{array}$ \\
\hline 2017 & $\begin{array}{l}\text { La Agencia, con corte a diciembre de } 2017 \text {, } \\
\text { participó en } 656 \text { procesos y casos cuyas pre- } \\
\text { tensiones sumaron } \$ 3.315 \text { billones, lo que } \\
\text { equivale a un } 87 \% \text { del valor de las pretensio- } \\
\text { nes de todas las demandas contra el Estado, } \\
\text { las cuales arrojaron un total de } 450.039 \text { pro- } \\
\text { cesos, con pretensiones por valor de } \$ 3.791,1 \\
\text { billones (ANDJE, 2017). }\end{array}$ & $\begin{array}{l}\text { El presupuesto de toda la Nación para el año } 2017, \\
\text { según lo expuesto por el Ministerio de Hacienda } \\
\text { en el Decreto } 2170 / 2016 \text {, por el cual se liquidó el } \\
\text { Presupuesto General de la Nación para la vigencia } \\
\text { fiscal de } 2017 \text {, equivalió a: doscientos veinticuatro bi- } \\
\text { llones cuatrocientos veintiún mil seiscientos setenta y } \\
\text { dos millones trescientos doce mil seiscientos noventa } \\
\text { y siete pesos moneda legal ( } \$ 224,421,672,312,697) \text {. }\end{array}$ \\
\hline
\end{tabular}




\begin{tabular}{|l|l|l|}
\hline AÑo & \multicolumn{1}{|c|}{ PASIVO CONTINGENTE } & $\begin{array}{l}\text { MONTO DEL PRESUPUESTO GENERAL } \\
\text { DE LA NACIÓN, SEGÚN EL MINISTERIO } \\
\text { DE HACIENDA }\end{array}$ \\
\hline 2018 & $\begin{array}{l}\text { La Agencia participó en 304 procesos con } \\
\text { pretensiones por } \$ 3.193,75 \text { billones de pesos } \\
\text { (ANDJE, 2018). }\end{array}$ & $\begin{array}{l}\text { El presupuesto de toda la Nación para el año 2018, } \\
\text { según lo expuesto por el Ministerio de Hacienda } \\
\text { en el Decreto 2236/2017, por el cual se liquidó el } \\
\text { Presupuesto General de la Nación para la vigen- } \\
\text { cia fiscal de 2018, equivalió a: doscientos treinta } \\
\text { y cinco billones quinientos cincuenta y tres mil } \\
\text { ochocientos seis millones setecientos veintinueve } \\
\text { mil ochocientos sesenta y un pesos moneda legal } \\
(\$ 235,553,806,729,861) .\end{array}$ \\
\hline
\end{tabular}

Fuente: Elaboración propia.

Los datos aludidos demuestran que la justificación de la Sostenibilidad Fiscal y del IIF por parte del Gobierno y de los Congresistas que apoyaron la iniciativa legislativa, por lo menos desde una perspectiva netamente económica, financiera y contable, tenia asidero y sustento real. Sin embargo, dentro de los debates del Acto Legislativo 003/2011, así como en las sentencias dictadas por la Corte Constitucional (C- 1052/2012, C- 288/2012, C- 870/2014) y, mediante las cuales avalaron constitucionalmente las dos figuras mencionadas, no se hace alusión directa sobre el particular.

La única referencia se encuentra en el salvamento de voto realizado por el magistrado Humberto Sierra Porto, a la sentencia C132/2012, que en la parte resolutiva decidió inhibirse para conocer de los cargos invocados por los demandantes. Allí al exponer lo que debía entenderse por Sostenibilidad Fiscal, trajo a colación un informe del Banco Central Europeo, respecto de algunos países de la Zona Euro, en el que ese ente percibía la existencia de riesgos para la preservación de estabilidad fiscal, a saber: (i) la deuda de las administraciones públicas; (ii) los pasivos contingentes; y los (iii) pasivos implícitos $(\mathrm{p}, 45)$.

Con todo y lo anterior, a continuación se procederá a estudiar los alcances reales que ha tenido la jurisprudencia dictada por el Consejo de Estado y la Corte Constitucional, frente a los ciudadanos colombianos, como destinatarios finales de los derechos reconocidos en las sentencias judiciales, luego de seis años de promulgado el Acto Legislativo 03/2011, con el objetivo de exponer de la forma más objetiva posible, si los temores de la mayoría de autores citados tienen asidero, es decir, si en verdad el IIF solo produce efectos adversos, o si por el contrario, aquellos no han pasado de ser más que simples especulaciones.

\subsection{Desde la creación del IIF con el Acto Legislativo 03/2011, al año 2017, se han proferido dos sentencias, una por el Consejo de Estado, otra por la Corte Constitucional.}

\subsubsection{Sentencia Uno. El fallo condenatorio del Consejo de Estado en contra del Distrito Capital por el derrumbe del relleno sanitario "Doña Juana". (Radicado IJ 25000-23-26-000- 1999-00002-05/2014)}

Mediante sentencia del $1^{\circ}$ de noviembre de 2012, el Consejo de Estado falló en segunda instancia el proceso que perseguía el reconocimiento y pago de los daños y perjuicios causados a un grupo de ciudadanos afectados con el derrumbe del relleno sanitario "Doña Juana", acaecido el 27 de septiembre de 1997. En ésa decisión condenó al Distrito Capital a pagar una indemnización equivalente a doscientos veintisiete mil cuatrocientos cuarenta millones quinientos once mil cuatrocientos pesos (\$227.440.511.400).

El dinero debía entregarse dentro de los diez (10) días siguientes a la ejecutoria, al Fondo para la Defensa de los Derechos e Intereses Colectivos, administrado por el Defensor del Pueblo, quien conforme a lo ordenado en el artículo 65-3 de la Ley 472/1998, es el encargado de pagar de forma individual la indemnización reconocida a cada uno de los demandantes.

Ante la magnitud de la condena que avizoraba una eventual afectación de las finanzas del Distrito 
Capital para las vigencias presupuestales 2013 y 2014, que impediría la plena ejecución del plan de desarrollo, el Alcalde Mayor solicitó al Procurador General de la Nación invocar el IIF, para lograr la modulación de la condena impuesta.

Ese servidor atendió el llamado y radicó la solicitud; en ese orden, luego de analizar los pormenores del IIF, la solicitud presentada por el Procurador, así como la postura asumida por las partes durante el trámite procesal, en sentencia del 25 de noviembre de 2014, el Consejo de Estado concluyó que pagar la condena tal y como había sido dictada, en efecto, afectaría la economía del Distrito Capital, principalmente el componente social, ya que para su cumplimiento debían llevarse a cabo traslados presupuestales.

Bajo estos derroteros, moduló la sentencia proferida el $1^{\circ}$ de noviembre de 2012 , la que finalmente quedó de la siguiente forma:

DISPONESE que, a más tardar al 31 de diciembre de 2014, por lo menos el 50\% del monto de la indemnización colectiva objeto de esta condena será entregado al FONDO PARA LA DEFENSA DE LOS DERECHOS E INTERESES COLECTIVOS administrado por el Defensor del Pueblo, y a cargo del cual se pagarán las indemnizaciones, según lo ordenado en el artículo 65-3 de la Ley 472 de 1998. La suma restante se desembolsará a más tardar al 31 de enero de 2015. Del mismo modo, ordenó que la condena se actualizara desde la fecha en que se dictó la sentencia primigenia y la fecha de pago (Consejo de Estado, 2012: 72).

Como se observa, el Consejo de Estado le otorgó al Distrito dos plazos para solventar el pago total de la sentencia; sin embargo, lo acaecido durante el trámite del IIF en el asunto referido merece algunos comentarios especiales, como se pasa a exponer:

En primer lugar, debe resaltarse que, desde el momento en que se dictó la sentencia condenatoria al Distrito Capital a pagar la indemnización en favor de las víctimas del derrumbe del relleno sanitario Doña Juana $-1^{\circ}$ de noviembre de $2012-$, y hasta le fecha en que de forma definitiva se decidió si se acogían o no las peticiones del IIF -25 de noviembre de 2014-, transcurrió un tiempo superior a los dos años, durante el cual, sus efectos estuvieron suspendidos.
Esa situación puso de manifiesto que, ante lo complejo de la solicitud que sustentó el IIF, la alta corporación debió tomarse en su análisis y decisión un buen tiempo; de otro modo, no podría haber resuelto de forma certera, argumentada y objetiva la petición, dado que es apenas lógico que dicho escrito debía mostrar cómo se iban a desequilibrar las finanzas de la entidad territorial, a través de estudios técnicos, contables y financieros apoyados en robustas cifras económicas, y en el respectivo plan de desarrollo.

Lo que precede, conllevó a que los beneficiarios de la condena, tuvieran que esperar a que la solicitud del IIF se resolviera de fondo para poder acceder materialmente a su contenido específico reconocido.

En segundo lugar, importa precisar que el Procurador, en la solicitud del IIF, alegó que al Distrito Capital se le desajustarían las vigencias presupuestales de los años 2013 y 2014 y presupuestó dentro del plan de pago que propuso para satisfacer la suma de dinero reconocida como indemnización, que un primer desembolso se llevaría a cabo en el mes de febrero de 2013, por un valor de seis mil millones de pesos $(\$ 6.000 .000 .000)$. Pues bien, dicho plazo ni siquiera debió tomarse en consideración, en razón a que como ya se anotó, el IIF se decidió de forma definitiva en noviembre de 2014, fecha muy posterior a la propuesta por el Ministerio Público, para proceder al pago inicial.

En tercer lugar, el IIF estudiado por el Consejo de Estado, solamente le otorgó al Distrito Capital dos plazos para llevar a cabo la cancelación de la condena, con una diferencia entre cada uno de estos, de apenas un mes, de tal manera que, cabe preguntarse si el largo periodo de tiempo que la corporación tardó en decidirlo, realmente valió la pena en contraste con el corto término concedido al ente Distrital para honrar su obligación judicial. La respuesta es negativa, ya que con la indexación ordenada, la condena resultó ser más onerosa y en términos sencillos, no se protegieron las finanzas de la capital, conclusión que se pasa a desarrollar con más detalles.

En sintonía con lo anterior, y como un cuarto argumento, se insiste en que entre la emisión de la condena en noviembre de 2012 y la resolución definitiva del incidente en noviembre de 2014, 
transcurrió un poco más de dos años; lo expuesto, a primera vista supondría un plazo mayor para que el Distrito efectuara los traslados, adiciones y demás movimientos presupuestales necesarios para su cumplimiento. No obstante, ello no fue tan benéfico para la entidad, en atención a que el Consejo de Estado le ordenó actualizar la condena desde la fecha de emisión hasta cuando se acreditara su pago a la Defensoría del Pueblo, lo que desembocó en un monto de dinero adicional bastante oneroso para sus finanzas, simplemente por el gran valor a indexar -doscientos veintisiete mil cuatrocientos cuarenta millones quinientos once mil cuatrocientos pesos $(\$ 227.440 .511 .400)$ - Al Aplicar la fórmula de indexación expuesta por el Consejo de Estado en el fallo en estudio:

$$
\mathrm{VP}=\mathrm{VH} \frac{\text { Índice Final }}{\text { Índice Inicial }}
$$

Resulta que el primer desembolso, que debía pagarse en diciembre del año 2014 fue de ciento veinte mil doscientos setenta millones ochocientos cincuenta y ocho mil setecientos cincuenta y cuatro pesos $(\$ 120,270,858,754)$, esto es, seis mil quinientos cincuenta millones seiscientos tres mil cero cincuenta y cuatro pesos $(\$ 6,550,603,054.00)$, adicionales sobre la condena inicial. El segundo desembolso que debió llevarse a cabo el 31 de enero de 2015, fue de ciento veintiún mil cuarenta y cinco millones setecientos cincuenta y dos mil quinientos cincuenta y dos pesos $(\$ 121,045,752,552)$, es decir, siete mil trescientos veinticinco millones cuatrocientos noventa y seis mil ochocientos cincuenta y dos pesos $(\$ 7,325,496,852)$, de más sobre la condena inicial. En suma, el Distrito Capital, por indexación debió pagar un total de trece mil ochocientos setenta y seis millones cero noventa y nueve mil novecientos seis pesos $(\$ 13,876,099,906.00)$.

A continuación se expone el gráfico número 1, que se denomina indexación de la condena ${ }^{3}$ :

3. Fuente: Elaboración propia

\begin{tabular}{|c|c|c|}
\hline OPERACIONES ARITMETICAS DE LA INDEX & DE DICIEMBRE DE 2014 & \\
\hline \begin{tabular}{|c|} 
DESCRIPCION \\
\end{tabular} & VALOR & \\
\hline CAPITAL & $113,720,255,700.00$ & \\
\hline & $\mathbf{V H}$ & $113,720,255,700.00$ \\
\hline & IPCI : 1-11-2012 & 111.71648 \\
\hline VP= VALOR PRESENTE & IPCF: 31-12-2014 & 118.15166 \\
\hline VH= VALOR HISTORICO (valor deuda) & & \\
\hline IPCI = INDICE PRECIOS CONSUMIDOR INICIAL & & \\
\hline IPCF= INDICE PRECIOS CONSUMIDOR FNAL & Fecha de Liquidación & $22 / 08 / 2017$ \\
\hline & TOTAL A 31-12-2014 & $\$ 120,270,858,754$ \\
\hline
\end{tabular}

\begin{tabular}{|l|c|}
\hline VP $=$ & VHxIPCF/IPCI \\
\hline VP $=$ & $120,270,858,754$ \\
\hline
\end{tabular}

\begin{tabular}{|l|r|}
\hline SUBTOTAL DEUDA & $\$ 120,270,858,754$ \\
\hline
\end{tabular}

\begin{tabular}{|l|r|}
\hline TOTAL A 31-12-2014 & $\$ 120,270,858,754$ \\
\hline
\end{tabular}

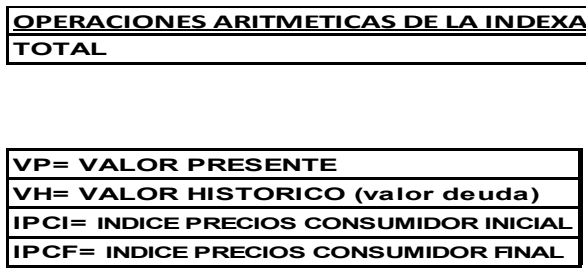

1 DE ENERO DE 2015

$113,720,255,700.00$

F $=$ INDICE PRECIOS CONSUMIDOR FINAL

\begin{tabular}{|l|r|}
\hline VH & $113,720,255,700.00$ \\
\hline IPCI : 1-11-2012 & 111.71648 \\
\hline IPCF: 31-01-2015 & 118.9129 \\
\hline
\end{tabular}
\begin{tabular}{|l|}
\hline \multicolumn{2}{|l|}{ Fecha Liquidación } & $22 / 08 / 2017$ \\
\hline
\end{tabular}

\begin{tabular}{|c|c|}
\hline VP= & VHXIPCF/IPCI \\
\hline VP= & $121,045,752,552$ \\
\hline
\end{tabular}

\begin{tabular}{|l|r|}
\hline SUBTOTAL DEUDA & $\$ 121,045,752,552$ \\
\hline
\end{tabular}

\begin{tabular}{|l|l|}
\hline TOTAL A 31-01-2015 & $\$ 121,045,752,552$ \\
\hline
\end{tabular}

Gráfico 1. Indexación de la condena. Elaboración propia 
Significa lo anterior que en lugar de ahorrarle dinero al Distrito Capital, en la práctica se terminó condenándolo al pago de una mayor cantidad, a su vez, a los demandantes se les suspendió en el tiempo la materialización de su derecho judicialmente reconocido, porque a pesar de que se ordenó que la condena se indexara al día de su pago, durante el tiempo de trámite del IIF estuvieron en incertidumbre, ya que sus efectos se suspendieron y solo contaban con la expectativa de algún día ser reparados integralmente por los daños y perjuicios reconocidos luego de un litigio de 15 años.

En ese contexto, se tiene que no se protegieron los derechos de los beneficiarios del fallo como ya se indicó, y menos aún del resto del conglomerado social, ya que el pago de la indexación debió salir del presupuesto público del Distrito Capital que, en últimas, pertenece a todos sus habitantes.

\subsubsection{Providencia Dos. El IIF sobre la sentencia de la Corte Constitucional C- 492/2015 del 15 de agosto, que ordenó la sustracción de las rentas de trabajo exentas, en los métodos "IMAN e IMAS- $P E^{\prime \prime}$ para el cálculo del impuesto a la renta}

En ese pronunciamiento, la Corte declaró la exequibilidad condicionada del artículo 10 de la Ley 1607/2012, modificado por el artículo 33 de la Ley 1739/2014 y dispuso:

que a partir del periodo gravable siguiente a aquel en que se expide este fallo, el cálculo de la renta gravable alternativa para empleados, obtenida en virtud de los sistemas IMAN e IMAS-PE, debe permitir la sustracción de las rentas de trabajo exentas, en los términos previstos por el artículo 206-10, primera frase, del Estatuto Tributario, una vez se detraigan del valor total de los pagos laborales recibidos por el trabajador, los conceptos permitidos por el artículo 332 del Estatuto (Corte Constitucional, Sentencia C- 492/2015: 86).

En concreto, a esa conclusión arribó el Tribunal Constitucional al encontrar que la regulación analizada estaba llamada a interferir en el mínimo vital de los contribuyentes con niveles medios de renta, amenazando su goce efectivo (Corte
Constitucional, Sentencia C-492/ 2015, Párrafo. 57.2: 80).

Contra esa decisión, el Ministro de Hacienda tramitó el IIF, y sostuvo que el fallo constituía un grave impacto para las finanzas del Estado, ya que en su concepto y en el de la DIAN, el impacto fiscal anual sería aproximadamente de 335 mil millones de pesos (Corte Constitucional, Auto 233/2016).

En la sustentación, que se encuentra resumida en el Auto 184/2016, El ministro expuso en suma, los siguientes argumentos:

El impacto sobre las finanzas no resulta, en sí mismo, del tamaño de la pérdida producida por la sentencia C-492/2015, sino del contexto en el cual se presenta, y lo que significa en esa atmósfera económica pues puede ser elemento catalizador de un peligroso proceso de estancamiento económico y pérdida de ingresos fiscales. La aplicación del fallo se estima en una disminución de \$335 mil millones en recaudo tributario. El fallo se expide en el marco de una caída de los precios del petróleo hasta ubicarse en mínimos históricos, que representa una pérdida de $\$ 22,2$ billones en el lapso 2013-2016. El contexto en el cual se tienen que absorber los efectos del fallo está marcado por la devaluación y la inflación. Desde mediados de 2014, los principales socios comerciales de Colombia; es decir, Estados Unidos y China, han experimentado respectivamente procesos de normalización monetaria y desaceleración económica, los cuales han causado choques externos a la economía colombiana, con una reducción en los ingresos de más de $\$ 20$ billones entre 2013 y 2016 (Corte Constitucional, Auto 184/2016: 26).

A su vez, el ministro precisó cuatro aspectos del impacto sobre la Sostenibilidad Fiscal: i) los instrumentos de programación fiscal de la Nación representados en el Marco Fiscal de Mediano Plazo y en la Regla Fiscal, que se pone en riesgo; ii) los efectos de la caída de los precios del petróleo y la desaceleración de la economía en el recaudo tributario; iii) las alternativas planteadas por el Gobierno para enfrentar estos hechos y iv) el efecto de desviación del plan financiero que produce la sentencia C-492/2015 (Corte Constitucional, Auto 184/2016: 26). 
El Incidente se admitió mediante auto $184 / 2016$ y a partir de esa fecha los efectos de la sentencia fueron suspendidos. Asimismo, a través de auto 233/2016, la Corte accedió a diferir los efectos de la sentencia C- 492/2015 hasta el 31 de diciembre de 2016.

De entrada, se destaca la rapidez con que el fallo fue emitido, ya que el IIF se admitió en abril de 2016, y para el mes de junio del mismo año se resolvió.

La Corte Constitucional, al aceptar los argumentos del Ministerio de Hacienda y, por ende, al haber diferido por un periodo gravable adicional (a partir del año fiscal 2017), el cálculo de la renta gravable para empleados bajo los sistemas "IMAN e IMAS- PE", en el trasfondo afectó y restringió el derecho otorgado a los declarantes del tributo referido de sustraer sus rentas de trabajo exentas; posibilidad que en la práctica se traducía en menos dinero por declarar y pagar.

Ahora bien, de conformidad con la Constitución Política de 1991, artículo 338, inciso 3 , que establece el principio de no retroactividad tributaria, las leyes que regulen contribuciones en las que la base sea el resultado de hechos ocurridos durante un período determinado, no pueden aplicarse sino a partir del período que comience después de iniciar la vigencia de la respectiva ley.

Lo anterior significa que los mandatos de la Sentencia C-492/2015, al ser diferidos hasta el 31 de diciembre de 2016, sólo aplicaron para el periodo gravable 2017, que para el caso del impuesto a la renta se declaró y pagó en 2018.

Lo descrito no tendría mayores inconvenientes, si no fuera porque mediante la Ley $1819 / 2016$, se reformaron los métodos que se tenían establecidos para determinar el impuesto a la renta y sobre los que la Corte Constitucional se pronunció (IMAN e IMAS- PE), por un sistema que se denominó "cedular". Así las cosas, las previsiones de la citada sentencia de constitucionalidad en la práctica para los ciudadanos declarantes del impuesto a la renta periodo fiscal año 2017, fueron por decir lo menos; inanes.

Lo antedicho obedece en términos sencillos, a que la norma aplicable para la declaración de renta del año 2017, que se presentó en el año
2018, fue la Ley 1819/ 2016, que derogó los métodos "IMAN e IMAS-PE" y sobre los que la Corte en sentencia C-492/2015, había otorgado el derecho de permitir la sustracción de las rentas de trabajo exentas en la respectiva declaración.

Sobre el tópico anterior, de forma certera, Arango (2012) advirtió que luego del Acto Legislativo 03/2011, era posible que el cumplimiento de una sentencia que reconocía un derecho se viera diferido por razones económicas, terminando por imponerse el equilibrio fiscal sobre el goce efectivo del derecho ciudadano; sin contar con la aceptación de las personas afectadas en sus derechos judicialmente reconocidos. En este sentido, estimó que el IIF estaba en contravía del Pacto Internacional de Derechos Económicos, Sociales y Culturales, dado que conllevaba a una regresión del nivel de garantía de los derechos alcanzados hasta el momento y, no se demostró durante el trámite de la reforma, mediante una argumentación clara y convincente, la imperiosa necesidad de retroceder en el nivel de garantía de los derechos. A modo de ejemplo sostuvo que el reconocimiento de derechos fundamentales por las Altas Cortes pesa menos que otros rubros del presupuesto de gastos públicos, como los son la deuda externa y los gastos militares (p, 20-23).

\subsubsection{Los intentos fallidos del IIF en la Corte Constitucional}

Han sido varias las ocasiones en que se ha acudido ante la Corte Constitucional solicitando la apertura y tramite del IIF; no obstante, esas pretensiones únicamente salieron abantes en el caso de la sentencia C- 492/2015, antes analizada. A continuación, en la tabla número 2 , se analizará esta situación: 
TABLA 2. SENTENCIAS SOBRE LAS QUE SE SOLICITÓ EL IIF

\begin{tabular}{|c|c|c|c|}
\hline $\begin{array}{l}\text { SENTENCIA SOBRE LA } \\
\text { QUE SE SOLICITÓ EL IIF }\end{array}$ & $\begin{array}{l}\text { PROVIDENCIA } \\
\text { QUE RESOLVIÓ }\end{array}$ & $\begin{array}{l}\text { SENTIDO DE } \\
\text { LA DECISIÓN }\end{array}$ & MOTIVOS \\
\hline $\begin{array}{l}\text { Sentencia C-101/2013, que or- } \\
\text { denó a la Procuraduría General } \\
\text { de la Nación que en un término } \\
\text { máximo de seis meses, con- } \\
\text { vocar a un concurso público } \\
\text { para la provisión en propiedad } \\
\text { de los cargos de Procurador } \\
\text { Judicial. }\end{array}$ & $\begin{array}{l}\text { Auto 168/2014 (4 de } \\
\text { junio) }\end{array}$ & $\begin{array}{l}\text { Declaró desierto el } \\
\text { IIF. }\end{array}$ & $\begin{array}{l}\text { Una vez concedida la apertura } \\
\text { del IIF, dentro de los } 30 \text { días } \\
\text { siguientes éste no se sustentó. }\end{array}$ \\
\hline $\begin{array}{l}\text { T-066 /2015, en la que ordenó } \\
\text { a la Registraduría Distrital de } \\
\text { Bogota, continuar con el trámi- } \\
\text { te de revocatoria del mandato } \\
\text { contra el alcalde Gustavo Petro } \\
\text { Urrego, dentro de un término } \\
\text { máximo de dos (2) meses. }\end{array}$ & $\begin{array}{l}\text { Auto 174/015 (6 de } \\
\text { mayo) }\end{array}$ & $\begin{array}{l}\text { Rechazó de plano } \\
\text { el IIF. }\end{array}$ & $\begin{array}{l}\text { La Corte Constitucional no } \\
\text { es competente para conocer } \\
\text { de los Incidentes de Impacto } \\
\text { Fiscal presentados contra } \\
\text { decisiones de tutela. }\end{array}$ \\
\hline $\begin{array}{l}\text { T-147/2013, dónde la Corte or- } \\
\text { denó a la Procuraduría General } \\
\text { de la Nación reintegrar a un } \\
\text { ciudadano y pagarle los sala- } \\
\text { rios y prestaciones dejados de } \\
\text { percibir desde el momento de } \\
\text { su desvinculación hasta su rein- } \\
\text { tegro; además, que, en máximo } \\
6 \text { meses, iniciara los trámites } \\
\text { para convocar el concurso pa- } \\
\text { ra proveer todos los cargos de } \\
\text { carrera que eran ejercidos en } \\
\text { provisionalidad. }\end{array}$ & $\begin{array}{l}\text { Auto 369A/2015 (26 } \\
\text { de agosto) }\end{array}$ & $\begin{array}{l}\text { Rechazó por } \\
\text { improcedente. }\end{array}$ & $\begin{array}{l}\text { La Corte Constitucional no } \\
\text { es competente para conocer } \\
\text { de los Incidentes de Impacto } \\
\text { Fiscal presentados contra } \\
\text { decisiones de tutela. }\end{array}$ \\
\hline $\begin{array}{l}\text { Sentencia C-291/2015, en la que } \\
\text { se analizaron los artículos } 21 \text { y } \\
22 \text { de la Ley } 1607 / 2012 \text {. Por la } \\
\text { cual se expiden normas en ma- } \\
\text { teria tributaria y se dictan otras } \\
\text { disposiciones. }\end{array}$ & $\begin{array}{l}\text { Auto } 446 / 2015 \text { (30 } \\
\text { de septiembre) }\end{array}$ & Declaró desierto. & $\begin{array}{l}\text { Una vez concedida la apertura } \\
\text { del IIF, dentro de los } 30 \text { días } \\
\text { siguientes éste no se sustentó. }\end{array}$ \\
\hline $\begin{array}{l}\text { Sentencia SU 214/2016. En } \\
\text { esta providencia, la Corte } \\
\text { Constitucional abordó el siguien- } \\
\text { te problema jurídico: } \\
\text { ¿Celebrar un contrato civil de } \\
\text { matrimonio entre parejas del } \\
\text { mismo sexo, en lugar de una } \\
\text { unión solemne innominada, con } \\
\text { miras a suplir el déficit de pro- } \\
\text { tección declarado por la Corte en } \\
\text { Sentencia C-577 de } 2011 \text {, confi- } \\
\text { gura una violación del artículo } \\
42 \text { Superior, tal y como lo aducen } \\
\text { quienes se negaron a celebrar o a } \\
\text { registrar los matrimonios civiles } \\
\text { igualitarios?; o por el contrario, } \\
\text { como lo interpretaron los jueces } \\
\text { civiles que los celebraron, ¿cons- } \\
\text { tituye una adecuada interpre- } \\
\text { tación de la Sentencia C-577 de } \\
\text { 2011, un ejercicio válido de auto- } \\
\text { nomía judicial y una materializa- } \\
\text { ción de principios constituciona- } \\
\text { les como la igualdad, la libertad y } \\
\text { la dignidad humana? }\end{array}$ & $\begin{array}{l}\text { Autos 184A/2016 } \\
\text { (del } 28 \text { de abril)y } \\
021 / 2017 \text { (del } 26 \text { de } \\
\text { enero). }\end{array}$ & $\begin{array}{l}\text { Rechazó la solicitud } \\
\text { de apertura del } \\
\text { incidente. }\end{array}$ & $\begin{array}{l}\text { Las entidades solicitantes, } \\
\text { Fundación Marido y Mujer, } \\
\text { la Veeduría Ciudadana de la } \\
\text { Política Pública Nacional y } \\
\text { Territorial sobre la Familia, la } \\
\text { Vida Humana y la Convivencia } \\
\text { Ciudadana en Colombia y la } \\
\text { Red Familia Colombia, no } \\
\text { se encontraban legitimadas } \\
\text { por el artículo } 334 \text { de la } \\
\text { Constitución y los artículos } \\
1 \text { y } 4.1 \text { de la Ley } 1695 / 2013 \\
\text { para promoverlo. }\end{array}$ \\
\hline
\end{tabular}




\begin{tabular}{|l|l|l|l|}
\hline $\begin{array}{l}\text { SENTENCIA SOBRE LA } \\
\text { QUE SE SOLICITÓ EL IIF }\end{array}$ & $\begin{array}{l}\text { PROVIDENCIA } \\
\text { QUE RESOLVIÓ }\end{array}$ & $\begin{array}{l}\text { SENTIDO DE } \\
\text { LA DECISIÓN }\end{array}$ & \multicolumn{1}{c|}{ MOTIVOS } \\
\hline $\begin{array}{l}\text { Sentencia SU } 377 / 2014 \text { en a } \\
\text { que se analizaron acciones de } \\
\text { tutela de 609 ex empleados de } \\
\text { TELECOM contra el Patrimonio } \\
\text { Autónomo de Remanentes de } \\
\text { dicha entidad, pretendiendo el } \\
\text { amparo de sus derechos consti- } \\
\text { tucionales fundamentales. }\end{array}$ & $\begin{array}{l}\text { Auto } 116 / 2017 \text { del } \\
08 \text { de marzo. }\end{array}$ & $\begin{array}{l}\text { Rechazó la solicitud } \\
\text { de apertura del } \\
\text { incidente. }\end{array}$ & $\begin{array}{l}\text { El Jefe de la Oficina Jurídica } \\
\text { del MINTIC, no está legiti- } \\
\text { mado para interponer dicha } \\
\text { peticion y dicho trámite no } \\
\text { procede contra sentencias de } \\
\text { tutela. }\end{array}$ \\
\hline
\end{tabular}

Fuente: Elaboración propia.

Como se observa, ante la Corte Constitucional se ha solicitado en varias oportunidades la tramitación del IIF, pero por diferentes motivos, la corporación no accedió a esas peticiones. Lo anterior refleja en parte la postura de Gómez (2015), puesto que, el Estado Social de Derecho y sus principios básicos no se han trastocado, en la medida en que el IIF no ha tenido un gran número de decisiones de fondo y el hecho de que la Corte Constitucional lo haya vedado frente a las acciones de tutela le cortó de forma tajante y en gran parte los alcances que desde el Congreso se le pretendieron otorgar.

\section{CONCLUSIONES}

Durante el séptimo debate que se le impartió en el Senado de la República al Acto Legislativo $03 / 2011$, sin deliberaciones profundas y con la exclusión de la Cámara de Representantes, se estableció el IIF.

Este es un trámite que se inicia una vez que se notifica una sentencia por una Alta corporación judicial, a saber, la Corte Constitucional, el Consejo de Estado o la Corte Suprema de Justicia, con efectos serios sobre las finanzas del Estado.

La legitimación recae en el Procurador General de la Nación o en cualquiera de los ministros del Gobierno, quienes pueden solicitar que se modulen, modifiquen o difieran los términos ordenados para el cumplimiento de la sentencia.

Al seguir con la idea en exposición, es plausible indicar que le asiste razón a los doctrinantes que predijeron que el IIF era un retroceso para la autonomía judicial, la separación de poderes y en general para los derechos ciudadanos, por lo siguiente:
En el caso de la Sentencia C- 492/2015, la última palabra sobre la forma cómo debía aplicarse el IIF, recayó en el Gobierno, quien astutamente jugó con las prerrogativas otorgadas en esa figura, logrando que los alcances de la sentencia no se concretaran en beneficio de los ciudadanos, promoviendo una ley que le empató con los plazos durante los cuales se difirió la aplicación de los mandatos del fallo, llevando en la praxis a que no se pudieran aplicar. Así las cosas, sí se desdibujan los principios de separación de poderes, como lo pronosticaron Arango (2012), Roa (2015), Barbosa (2014), Rodríguez (2014), Aguilera (2014) y, Guerrero (2012).

El estudio efectuado demostró que el sentido de la decisión judicial implícitamente sí se modifica, ya que si bien en teoría los fallos sobre el IIF no pueden variarla, en la práctica ello sí ocurre, como se vio en la Sentencia C- 492/2015, caso en el que los ciudadanos no gozaron de la prerrogativa otorgada por la Corte Constitucional, sustracción de las rentas de trabajo exentas, para el cálculo del impuesto a la renta, vulnerándose el contenido del parágrafo del artículo $1^{\circ}$ de la Ley 1695/2013, según el cual, bajo ninguna circunstancia se podrá invocar la sostenibilidad fiscal para menoscabar los derechos, restringir su alcance o negar su protección efectiva. Por ende, le asiste razón a Restrepo (2015) y Barbosa (2014).

De otra parte, el fallo del Consejo de Estado evidenció una regresión en el nivel de garantía de los derechos alcanzados hasta el momento por los beneficiarios de la condena, quienes, en principio, debieron esperar un tiempo superior para acceder a las indemnizaciones, si bien, al final obtuvieron el dinero indexado, evitando la pérdida de valor adquisitivo, innegable es que existió un retardo en la satisfacción de sus derechos, en este sentido, 
surgen verdaderos los argumentos de Aguilera (2014) y Arango (2012).

Lo anterior, porque por un lado los beneficiarios de la condena del Relleno Sanitario Doña Juana, luego de litigar el proceso durante 12 años, debieron esperar en incertidumbre dos años más para que el incidente se resolviera, término durante el cual, el derecho a obtener la reparación de los daños y perjuicios causados no fue posible; de forma posterior, con la decisión del incidente, que se recuerda se inició para salvaguardar las finanzas del Distrito Capital, todos los habitantes de la entidad territorial se vieron afectados, pues si bien es cierto que se concedieron plazos adicionales para el pago, no es lo menos que se ordenó una indexación que conllevó un pago adicional de trece mil ochocientos setenta y seis millones cero noventa y nueve mil novecientos seis pesos $(\$ 13,876,099,906.00)$.

Bajo ese orden de ideas, después de la emisión del fallo por el Consejo de Estado y vistas sus nefastas consecuencias, tanto para los beneficiaros de la condena como para las finanzas Distritales, en adelante, las entidades deben valorar con mucho más tacto si en realidad vale la pena tramitar el IIF, pues les puede resultar más oneroso. Al parecer, la balanza se ha inclinado por no tramitarlos, así por lo menos lo demuestra la inexistencia de otros fallos sobre la materia en esta Corporación judicial.

En sintonía con Gómez (2015), es cierto que el IIF no ha tenido la potencialidad suficiente para acabar con los derechos sociales, con la acción de tutela o con el Estado social de derecho, simple y llanamente por la poca aplicabilidad que ha tenido, contexto que se refleja en el reducido número de sentencias hasta ahora expedidas en dos de las Altas Cortes con mayor incidencia en el gasto público a través de sus decisiones, sin embargo, del estudio de sus fallos, se encuentra que en la realidad, el IIF es problemático y realmente son pocos sus beneficios, en contraste con sus efectos adversos. En los dos proveídos analizados siempre se presentaron disminuciones, retardos e inaplicación de los derechos reconocidos a los asociados.

En resumidas cuentas, el IIF no es una figura que haya traído consecuencias positivas en la protección, materialización y efectividad de los derechos de los ciudadanos; de las jurisprudencias analizadas, se evidencia que sus efectos son adversos para los beneficiarios de la condena y para las finanzas de las entidades estatales.

Si bien es cierto, en el caso de la sentencia de la Corte Constitucional donde se difirió la aplicación de las exenciones dentro de los métodos "IMAN E IMAS- $P E$ ", el Estado salvaguardó sus finanzas, el contexto bajo el cual se logró mantener el recaudo tributario esperado no puede ser tolerado, ya que, estratégicamente, el Gobierno con la expedición de una nueva reforma tributaria y de paso de un nuevo método para calcular el impuesto a la Renta, burló abiertamente tanto el fallo de la Corte como el derecho concedido a los declarantes del tributo, situación inaceptable que refleja abiertamente la intromisión del ejecutivo dentro de las decisiones de los jueces, al decidir cómo, cuándo y de qué manera satisface los derechos reconocidos en sede judicial. Actuación que se reprocha, pues a diferencia de lo dicho por la Corte Constitucional al estudiar la constitucionalidad del IIF, la separación de poderes, así como la autonomía judicial, sí se han visto seriamente afectadas.

Por fortuna, actualmente los Incidentes de Impacto Fiscal no proceden contra las decisiones de tutela, porque allí al protegerse de forma directa derechos fundamentales, sus efectos habrían sido nefastos, y en cada decisión del Tribunal Constitucional en la que se impactara el presupuesto estatal, seguramente el Gobierno habría entrado a bloquearla.

En razón a todo lo antes indicado, el IIF debe desaparecer de nuestro ordenamiento jurídico, y en su lugar, adoptarse una nueva figura en la que todos los jueces de la República, no sólo las Altas Cortes como lo sostuvo López (2012), puedan solicitar dentro del trámite del proceso judicial, concepto no vinculante a la dependencia encargada de manejar las finanzas de la respectiva entidad a condenar, de tal manera que en el fallo se tengan en cuenta, como un parámetro más, las posibles consecuencias económicas, y de esta manera, si el Juez lo considera oportuno dentro de su autonomía judicial, establezca los criterios para los pagos. De esta forma se compaginan dos principios elementales sin vulnerar la separación de poderes, por un lado, el juez de forma libre e independiente determinará si es necesario otorgar plazos especiales para el cumplimiento de la condena y, por otro, salvaguardará los intereses económicos del Estado; de manera que 
tramitados todos los recursos en sede ordinaria se cierre definitivamente el proceso y las partes en contienda tengan certeza sobre el reconocimiento del derecho otorgado de una vez por todas desde la sentencia.

\section{BIBLIOGRAFÍA}

- Acevedo, D. (2015). La Sostenibilidad Fiscal en el Marco de las Decisiones de la Jurisdicción delo Contencioso Administrativo. Bogotá D.C. Universidad Militar Nueva Granada, Dirección de Postgrados Facultad de Derecho, Metodología de la Investigación. Especialización en derecho administrativo. Recuperado en 8 de febrero de 2020 de http://repository.unimilitar. edu.co/bitstream/10654/7602/1/ ACEVEDOGUTIE\%CC\%81RREZ.pdf.

- Agencia Nacional de Defensa Jurídica del Estado (ANDJE). (2012- 2016). INFORME DE GESTIÓN ANUAL. Recuperado en 15 de febrero de 2020 de http://defensajuridica. gov.co/gestion/informes/informesgestion/Paginas/default.aspx.

- Aguilera, J. (2014). Límites y Alcances del Principio de Sostenibilidad Fiscal en el Estado Social de Derecho. Bogotá. Maestría en Derecho Administrativo, Universidad Militar Nueva Granada. Recuperado en 21 de marzo de 2020 de http://repository.unimilitar. edu.co/bitstream/10654/11968/1/ L I M I T E S \% 20 Y \% 20 A L C A N C E S \% 20 D E L \% 20 P R I N C I P I O \% 20 D E \% 20 SOSTENIBILIDIAD\%20FISCAL\%20EN\%20 EL\%20ESTAD0\%20SOCIAL\%20DE\%20 DERECHO\%20\%281\%29.pdf.

- Álvarez, Y. (2012). Sostenibilidad Frente a los Derechos Fundamentales. Bucaramanga. Universidad Industrial de Santander, Facultad de Ciencias Humanas, Escuela de Derecho y Ciencia Política. Recuperado en 8 de abril de 2020 de http://tangara.uis.edu. co/biblioweb/tesis/2012/146792.pdf.

- Arango, R. (2011). Sustitución del Estado social de derecho por el Estadofiscal, en Revista Zero 27 (1): 70-72.ISSN:
0123-9779. Recuperado en 2 de marzo de 2020 de https://es.scribd.com/ document/230983441/15-RodolfoArango-Sustitucion-Del-Estado-Social-deDerecho-Por-Un-Estado-Fiscal1.

- ----. (2012). Derechos y Fines Políticos. Revista Jurídicas, 9 (1): 14-31. ISSN: 17942918. Recuperado en 15 de febrero de 2020 de http://juridicas.ucaldas.edu.co/ downloads/Juridicas9(1)_2.pdf.

- Barbosa F. (2014). La Sostenibilidad Fiscal: Desafío al Estado Social de Derecho en Colombia. Revista de Derecho Público (33): 1-23. Recuperado en 12 de abril de 2020 de https://derechopublico. uniandes.edu.co/index.php?option=com content $\&$ view $=$ article $\& i d=458 \% 3 \mathrm{Ala}-$ sostenibilidad-fiscal-desafio-al-estadosocial-de-derecho-en-colombia.

- Colombia, Congreso de la República. Comisión Primera Constitucional Permanente, Acta número 56/ 2011 de 25 de mayo Senado. Gaceta del Congreso 491/2011 del 11 de julio.

- -----. Exposición de Motivos. Proyecto de Acto Legislativo 016 de 2010 Cámara. Por el cual se establece el derecho a la sostenibilidad fiscal para alcanzar los fines del estado social de derecho. Recuperado en 15 de abril de 2020 de http://www. imprenta.gov.co/gacetap/gaceta.mostrar_ documento?p_tipo $=03 \&$ p_numero $=016 \& p_{-}$ consec $=26166$.

- -----. Gaceta 491 de 2011 del 11 de julio. Comisión Primera Constitucional Permanente Senado Acta 56 de 2011. Recuperado en 6 de mayo de 2020 de http://www.imprenta.gov.co/gacetap/ gaceta.indice?v_num=491\&v_anog=2011.

- -----. Acto Legislativo 003 de 2011, del 01 
de julio, $\cdot$ Por el cual se establece el Principio de la Sostenibilidad Fiscal. Recuperado en 7 de abril de 2020 de http://www. imprenta.gov.co/gacetap/gaceta.mostrar_ documento?p_tipo $=03 \& p_{-}$numero $=016 \& p_{-}$ consec $=26166$.

- -----. Ley 1695 de 2013. Por medio de la cual se desarrolla el artículo 334 de la Constitución Política y se dictan otras disposiciones.

- -----. Ley 472 de 1998. Por la cual se desarrolla el artículo 88 de la Constitución Política de Colombia en relación con el ejercicio de las acciones populares y de grupo y se dictan otras disposiciones.

- ------ Ley 1607 de 2012. Por la cual se expiden normas en materia tributaria y se dictan otras disposiciones.

- -----. Ley 1739 de 2014. Por medio de la cual se modifica el Estatuto Tributario, la Ley 1607 de 2012, se crean mecanismos de lucha contra la evasión y se dictan otras disposiciones.

- -----. Ley 1819 de 2016. Por medio de la cual se adopta una reforma tributaria estructural, se fortalecen los mecanismos para la lucha contra la evasión y la elusión fiscal, y se dictan otras disposiciones.

- Colombia. Presidencia de la República. Decreto 262 de 2000. Por el cual se modifican la estructura y la organización de la Procuraduría General de la Nación y del Instituto de Estudios del Ministerio Público; el régimen de competencias interno de la Procuraduría General; se dictan normas para su funcionamiento; se modifica el régimen de carrera de la Procuraduría General de la Nación, el de inhabilidades e incompatibilidades de sus servidores $\mathrm{y}$ se regulan las diversas situaciones administrativas a las que se encuentren sujetos.

- -----. Decreto 262 de 2000. Por el cual se modifican la estructura y la organización de la Procuraduría General de la Nación y del
Instituto de Estudios del Ministerio Público; el régimen de competencias interno de la Procuraduría General; se dictan normas para su funcionamiento; se modifica el régimen de carrera de la Procuraduría General de la Nación, el de inhabilidades e incompatibilidades de sus servidores $\mathrm{y}$ se regulan las diversas situaciones administrativas a las que se encuentren sujetos.

- -----. Decreto 2710 de 2014. Por el cual se liquida el Presupuesto General de la Nación para la vigencia fiscal de 2015, se detallan las apropiaciones y se clasifican y definen los gastos.

- -----. Decreto 3036 de 2013. Por el cual se liquida el Presupuesto General de la Nación para la vigencia fiscal de 2014, se detallan las apropiaciones y sé clasifican y definen los gastos.

- -----. Decreto 2715 de 2012. Por el cual se liquida el Presupuesto General de la Nación para la vigencia fiscal de 2013, se detallan las apropiaciones y se clasifican y definen los gastos.

- -----. Decreto 4970 de 2011. Por el cual se liquida el Presupuesto General de la Nación para la vigencia fiscal de 2012, se detallan las apropiaciones y se clasifican y definen los gastos.

- Colombia. Rama Judicial del Poder Público, Corte Constitucional. Sentencia C- 288 de 2012. M.P. Luis Ernesto Vargas Silva.

- -----. Sentencia C- 1052 de 2012. M.P. Jorge Ignacio Pretelt Chaljub.

- -----. Sentencia C- 870 de 2014. M.P. Luis Guillermo Guerrero Pérez.

- -----. Sentencia C- 783 de 1999. M.P. Álvaro Tafur Galvis.

- -----. Sentencia C- 492 de 2015. M.P. María Victoria Calle Correa.

- -----. Sentencia C- 101 de 2013. M.P. Mauricio González Cuervo.

- -----. Sentencia C- 291 de 2015. M.P. Gloria Stella Ortiz Delgado. 
- ------. Sentencia SU 377 de 2014. M.P. María Victoria Calle Correa.

- -----. Sentencia T $\quad-147$ de 2013. M.P. Jorge Ignacio Pretelt Chaljub.

- -----. Sentencia T-066 de 2015. M.P. Gloria Stella Ortiz Delgado.

- -----. Auto 233 de 2016. M.P. Luis Guillermo Guerrero Pérez.

- -----. Auto 184 de 2016. M.P. María Victoria Calle Correa.

- -----. Auto 168 de 2014. M.P. Mauricio González Cuervo.

- -----. Auto 174 de 2015. M.P. Gloria Stella Ortiz Delgado.

- -----. Auto 369 A de 2015. M.P. Jorge Ignacio Pretelt Chaljub.

- -----. Auto 446 de 2015. M.P. Gloria Stella Ortiz Delgado.

- -----. Auto 116 de 2017. M.P. María Victoria Calle Correa.

- Colombia. Rama Judicial del Poder Público, Consejo de Estado. Sentencia CONSEJO DE ESTADO, IJ 25000-23-26-000-1999-0000205 C.P. Enrique Gil Botero.

- García Pérez, M. (2013). El silencio administrativo en España. Revista Misión Jurídica, (6): 57 - 83. DOI: https://doi. org/10.25058/1794600X.62

- Gómez,J.(2015).ElCriteriodeSostenibilidad Fiscal: Un Cuestionamiento Sobre los Efectos del Acto Legislativo 03/ 2011. Revista de Derecho Público (35). Recuperado en 7 de abril de 2020 de https://derechopublico. uniandes.edu.co/index.php?option $=\mathrm{com}_{-}$ content\&view $=$ article $\& i d=549 \% 3 \mathrm{Ael}-$ criterio-de-sostenibilidad-fiscal-uncuestionamiento-sobre-los-efectos-delacto-legislativo-03-de-2011\&catid $=42 \%$ 3A35\&Itemid=132\&lang=es.

- Guerrero, A. (2012). Sostenibilidad fiscal y principios en el Estado Social de Derecho. Revista Criterio Jurídico, 12 (1). Recuperado en 6 de mayo de 2020 de: revistas.javerianacali.edu. co/index.php/criteriojuridico/article/ download/584/765.

- López, G. (2012). Los Derechos Sociales en Colombia y el Principio de Sostenibilidad Fiscal. Revista Dixi, 14 (15). Recuperado en 5 de enero de 2020 de https://revistas.ucc. edu.co/index.php/di/article/view/1011.

- Lozano, I., Ramírez, C. y Guarín, A. (2007). Sostenibilidad Fiscal en Colombia: una Mirada Hacia el Mediano Plazo. Revista Perfil de Coyuntura Económica (9): 47 - 72. Recuperado 10 de mayo de 2020 de https://aprendeenlinea.udea.edu.co/ revistas/index.php/coyuntura/article/ view/2325/1897.

- Lozano, I. y Cabrera, E. (2009). Una Nota Sobre la Sostenibilidad Fiscal y el Nexo Entre los Ingresos y Gastos del Gobierno Colombiano. Borradores de Economía, (579): 1-25. Recuperado en: http://www. banrep.gov.co/docum/ftp/borra579.pdf.

- Monroy, A. (2014). Interpretación Jurídica que Sustentaría un Incidente de Impacto Fiscal Frente a la Posición Jurídica del Consejo de Estado del 4 de agosto de 2010, Respecto de la Liquidación de las Pensiones del Sector Público. Bogotá D.C. Universidad Nacional de Colombia, Facultad de Derecho, Ciencias Políticas y Sociales. Recuperado 06 de mayo de 2020 de http://www.bdigital. unal.edu.co/46692/.

- ----. (2015). Los Techos Fiscales, Némesis de los derechos. Diálogos de Saberes (42). Recuperado 05 de mayo de 2020 de de: https://dialnet.unirioja.es/servlet/ articulo? codigo $=5479852$.

- Restrepo, J. (2015). Hacienda Pública. Décima Edición. Bogotá D.C.: Universidad Externado de Colombia.

- Roa, J. (2015). El Incidente de Impacto Fiscal y la Legitimidad Democrática de los Tribunales Constitucionales. Serie Documentos de trabajo (26): 1-23. Recuperado en 28 de febrero de 2020 de: http://www.academia.edu/12250117/ El_Incidente_de_Impacto_Fiscal_y_la_ 
legitimidad_democr\%C3\%A1tica_de_los_ tribunales_constitucionales.

- Rodríguez, J. (2014). La Sostenibilidad Fiscal, El Triunfo del Mercado Sobre los Derechos. Universidad Colegio Mayor De Nuestra Señora Del Rosario, Facultad de Jurisprudencia (Colombia). Recuperado en 12 de abril de 2020 de http://repository. urosario.edu.co/handle/10336/9653.

- Sánchez, D., Ricaute, S. y Castillo, D. (2012). Compatibilidad del Principio de
Sostenibilidad Fiscal y el Concepto de Estado Social de Derecho en Colombia. In Vestigium Ire, 5 (1). Recuperado 25 de abril de 2020 de http://revistas.ustatunja. edu.co/index.php/ivestigium/article/ view/607/698.

- Torres, U. (2015). Procedimiento en las Actuaciones Administrativas de Carácter Tributario. I Edición. Bogotá: Grupo Editorial Ibáñez. 